\title{
Territorio como medium: Discusión sobre rendimientos analíticos para las observaciones de la complejidad socio- espacial
}

\author{
Territory as Medium: Discussion on Analytical Performance for Observations of Socio-spatial \\ Complexity
}

\author{
María Antonieta Urquieta \\ Departamento de Trabajo Social, Universidad de Chile, Chile \\ César Mariñez \\ Departamento de Trabajo Social, Universidad de Chile, Chile \\ Catalina Jorquera \\ Departamento de Trabajo Social, Universidad de Chile, Chile
}

\begin{abstract}
RESUMEN
El objetivo del presente artículo es caracterizar al 'territorio' como medio y discutir sobre sus rendimientos analíticos para observar a la complejidad socio-espacial. En primer lugar, presentamos un bosquejo conceptual de la distinción medio/forma para entender esta propuesta en el marco de un abordaje de los fenómenos sociales (I). Luego caracterizamos al territorio como un medio para la construcción de formas y damos cuenta de las maneras en que los observadores construyen expectativas sobre lo que observan, cuando este se tematiza en la comunicación (II). A modo de conclusión, señalamos la relevancia que tiene el medio territorio para futuros estudios relacionados con la inclusión y la exclusión social.
\end{abstract}

Palabras Clave: Medio; Forma; Territorio; Complejidad socio-espacial, Complejidad territorial

\section{ABSTRACT}

The article characterize 'territory' as a medium and discuss its analytical advantages to observe sociospatial complexity. First, we present a conceptual outline for distinction medium/form to analyse social phenomena (I). Then we characterize territory as a medium for the construction of forms, and show the ways in which observers build expectations about what they observe when territory is thematized in communication (II). As conclusion, we discuss the relevance of territory for future researches on social inclusion and exclusion (III).

KEYWORDS: Medium; Form; Territory; Socio-spatial complexity; Territorial complexity

MAD, N 37 (2017), PP. 143-166

DOI: $10.5354 / 0718-0527.2017 .47279$

(C) CC BY-NC 3.0 CL 


\section{INTRODUCCIÓN ${ }^{1}$}

La pluridiversidad de problemáticas que se observan en la sociedad contemporánea urge a las ciencias sociales a introducir herramientas analíticas, teóricas, metodológicas y conceptuales en sus estudios, las cuales sean cada vez más atingentes a la complejidad creciente y no lineal de las relaciones sociales. Frente a este desafío, un elemento relevante y que ha sido escasamente estudiado es el 'territorio'. Al asumir el reto de observar su complejidad, se deben superar las perspectivas que lo posicionan como un mero escenario donde acontece lo social o como un lugar en el que se concentran determinadas problemáticas sociales.

El territorio es un plexo de múltiples interrelaciones, procesos o dinámicas sociales, y no una mera marcación de límites geográficos o una conglomeración de sujetos en un lugar (Santos 2000; Giménez 2000; Escobar 2010; Sarma, 2016). Los territorios no se describen únicamente como lugares que tienen identidad propia y que se diferencian de otros espacios por sus delimitaciones territoriales (Lindón, 2007; Gibler, Hutchison \& Miller 2012; Hensel \& McLaughlin 2016), sino que en ellos se observa también la existencia de "un entretejido de extensiones entre los espacios locales y globales que dan lugar a continuos procesos de deterritorializaciones/ desterritorializaciones/ reterritorializaciones" (Ther 2006: 109). Dichos procesos se hacen interesantes de abordar como foco de estudio, producto también de las problemáticas sociales que se ponen en juego en sus múltiples dinámicas, temporalidades y realidades.

Estas problemáticas se evidencian en una diversidad de investigaciones, como por ejemplo, sobre la migración (Giménez 2001; Sassone 2007; Anguiano 2008; Sobrino 2010; Quezada 2007; Awan \& Langley 2013; Collyer \& King 2014); la segregación, exclusión o marginación socio-espacial urbana o rural (Leal 2002; Sabatini 2003; Roitman 2003; Romero \& Vásquez 2005; Arapoglou 2012; Madaniour \& Weck 2015; Pizaña 2015), los problemas étnicos o culturales (De la Peña 1999; Aylwin 2000; Giménez 2001; Hoffman 2002; Sorens 2011; Velazco 2011; Piang 2015; Wacquant 2015), la desigual distribución territorial de oportunidades de acceso a empleos (McClure \& Clavo 2013; Mac-Clure, Barozet \& Maturana 2014; Ri-

\footnotetext{
${ }^{1}$ Este artículo ha sido posible gracias al apoyo del Proyecto Fondecyt de Iniciación en Investigación N¹1140551, "Operaciones de Inclusión/Exclusión en sistemas territoriales complejos. Marcos e instrumentos para la observación socio-espacial”. Investigadora responsable María Antonieta Urquieta Álvarez.
} 
misp 2013) o la persistente desigualdad territorial de la oferta o calidad de los servicios públicos (Matus 2009; Caquimbo 2009; Ezcurra 2014). Tampoco se puede olvidar que, cada vez más se pone el foco en la innovación social o en el uso de tecnologías para mejorar la calidad en los territorios (Kirat \& Lung 1999; MacCallum et al. 2008; Cannarella \& Piccioni 2007; Luukkonen 2014: Fixari \& Pallez 2016; Cortez \& Matus 2016; Vera 2017), sin apartar las propuestas investigativas que tienen como foco incidir en las políticas públicas (Boschken 2000; Parkinson 2013; Varela 2015). Todo parece indicar entonces que, para comprender o interpretar mejor a los territorios, se debe tomar en cuenta a las múltiples dimensiones sociales que emergen en la complejidad misma en la cual se desenvuelven las personas con sus instituciones, en su vínculo con sus límites materiales "naturales" o "creados" (Kollmann 2005).

Desde una visión más social, propuestas investigativas como las expuestas anteriormente son posibles también gracias a la diversidad de enfoques o perspectivas que sustentan sus premisas, las cuales buscan examinar con mayor consistencia los procesos sociales -en los territorios- que emergen de las condiciones estructurales de la sociedad (Adorno 2008). Estudios territoriales desde la dialéctica o el materialismo histórico (Holsrsen 2013; Guevara 2015), el funcionalismo (Oort, Burger \& Raspe 2010; Vasanen 2012; Burger \& Meijers 2012), el poscolonialismo o la biopolítica (Foucault 2006; Featherstone 2013; Connell 2013; Damjanov 2015), el capital cultural o espacial (Mace 2015; Wacquant 2017), el enfoque de derechos territoriales (Uitermark \& Nicholls 2015; Angell 2016), tendrán ese objetivo. La apuesta estará, en otras palabras, en darle vitalidad al territorio (Tello 2000), desde un posicionamiento más social y crítico, sin restar relevancia a los procedimientos, instrumentos metodológicos o estándares de las ciencias duras.

En esta diversidad de enfoques y propuestas investigativas, nos encontramos también con la noción de complejidad, la cual parece ser muy bien aceptada en los estudios socio-espaciales. Se cree que, con este concepto, es posible tener un mayor rendimiento para entender los fenómenos territoriales y así evitar caer en modelos lineales, predecibles o causales (Thrift 1999; Andrade et. Al. 2001; Suteneau 2005; O’Sullivan et al. 2006; Curtis \& Riva 2009; Leydesdorff \& Deakin 2011; Allen 2012). En otras palabras, desde una fundamentación "de lo impredecible, de una cuasi deflagración, en la agitación y la turbulencia, según encuentros aleatorios" (Morin 1995: 1), se buscará dar cuenta que la geografía es fragmentada (Allen 
2012), y desde este posicionamiento será posible estudiar detalladamente las características contextuales de las ubicaciones físicas para evidenciar que "los elementos del sistema [del territorio] están espacialmente estructuradas en formas que contribuyen también a la evolución de la estructura espacial en la que se desarrollan" (O’Sullivan et al. 2006: 612).

Siguiendo esta misma línea, buscaremos radicalizar la mirada desde una perspectiva sistémico-constructivista. Desde esta aproximación, se puede entender a la complejidad como partes o elementos que interactúan de una manera no simple, aleatoria o no lineal (Simon, en La Porte 1976). Sin embargo, esta interrelación de elementos se traduce, desde el enfoque propuesto, como un gran número observaciones policontexturales (Teubner 2005), que imposibilita la existencia de "un único "Lebenswelt", común a todos los observadores como referencia única, sino que partimos en nuestras observaciones de la pluralidad de mundos y de sistemas de referencias" (Pintos 1999: 3). En otras palabras, si la complejidad implica que "al aumentar el número de los elementos que deben mantenerse unidos en un sistema, se topa con un umbral en donde ya no es posible relacionar cada uno de los elementos" (Luhmann, 1998: 47), es porque se hace imposible observar simultáneamente a la multiplicidad de observadores que observan, pues "existen múltiples posiciones, las que conducen a disponer de muchas posibilidades para observar, sin poder indicar a ninguna como la más completa" (Arnold 2010: 6).

Este posicionamiento permitirá observar al territorio de otra manera; interesa comprender el proceso por el cual el territorio queda tematizado desde una pluralidad de perspectivas diversas que se reproducen comunicacionalmente, sin reducir la mirada a una mera interrelación de actores que se enfrentan a la incertidumbre o a la indeterminación en un territorio. Se cree que reducir la mirada a actores que interactúan entre sí, más allá de la incertidumbre o la indeterminación, limita la posibilitad de observar procesos mucho más diferenciados y desde múltiples posiciones distintas. Nos interesa en este sentido dar cuenta de cómo los observadores comunican sobre el territorio, más que observar actores en el territorio. Se propone es una lógica autológica cuando los sistemas refieren al espacio, para observar que son las observaciones (comunicaciones) las que indican una diferencia para cada observador sobre el territorio.

Para llegar a dicho objetivo, tomaremos prestada la distinción que propone Niklas Luhmann entre medium y forma para aplicarla a la complejidad territorial. Según, esta propuesta conceptual, el medium. 
Se caracteriza por una conexión muy débil entre los elementos (lose Kopplung) [mientras que], las formas dan densidad a las conexiones del medium en las configuraciones más rígidas (rigide Kopplugngen). El medium, por tanto, no tiene forma: el aire no es ruidoso y las ondas electromagnéticas no son luminosas. (Corsi, Esposito, Baraldi 2006: 114).

Nos apoyaremos en esta distinción para considerar -como explicaremos más adelante- al territorio como un medio para la construcción de formas. Como se verá, esta distinción sistémica es relevante, ya que se vincula fuertemente con el problema de la complejidad, en la medida en que los observadores que se orientan por los mediums no pueden seleccionar todas las formas cuando describen sus observaciones sobre el territorio.

La propuesta de este artículo es desarrollar un esbozo conceptual de la distinción medium/forma para entender cuáles son las ventajas para el abordaje de fenómenos sociales (I). Se aplicará luego dicha distinción para observar al territorio como un medium para la construcción de formas. Se verá en este punto que el territorio no solo es 'tema', sino que, con él, los observadores construyen expectativas sobre lo que observan cuando se participa en la comunicación desde el medium del territorio (II). A modo de conclusión, se identificarán algunos lineamientos claves que tiene el medium territorio para futuros estudios principalmente en relación con la inclusión y la exclusión social.

Esta propuesta busca ofrecer nuevas salidas conceptuales que nos permitan explicar con mayor rendimiento a las complejidades territoriales a través de un enfoque teórico que apuesta por observar fenómenos complejos de una manera mucho más radical: desde un posicionamiento autológico mediante la distinción medium/forma. Por último, esta propuesta pretende seguir profundizando en los estudios territoriales desde un enfoque sistémico, ya que son pocas las investigaciones que vinculan esta perspectiva con el territorio (Pfeilstetter 2011; Leydesdorff \& Deakin 2011; Mascareño 2011). Adoptando esta perspectiva, se podrán gatillar nuevas propuestas investigativas en la línea de la complejidad territorial.

\section{LOS MEDIUMS Y SUS MÚLTIPLES FORMAS}

Los mediums hacen referencia a aquellos significados que potencialmente se condensan en el tiempo para uno poder "describir una situación como 
descripción de una condición” (Foerster 2014: 41). Como condensaciones potenciales, ofrecen "una posibilidad definida de hacer posible posibilidades indefinidas de posibilidades" (Krause, en Tyulenev 2012: 88), para uno arrojarse a una multiplicidad de circunstancias que nos son familiares, o para tolerar formas que se actualizan sobre el mundo en nuestras relaciones sociales (Luhmann 1998). La reproducción cultural que se construye con nuestros hábitos de rutina en el tiempo (Bourdieu 1997, 2008), los rituales en las experiencias cotidianas (Goffman 1967) o los imaginarios sociales que se actualizan para creer en los distintos universos simbólicos de la sociedad (Pintos 1995), son posibles con la ayuda de los mediums. A través de ellos se abren condiciones para "crear un universo a través de una distinción" (Von Foerster, en Cerutti 2000: 32), como una "construcción o proyección propia de un observador" (Corsi 2012: 85). También hacen posible que los observadores, desde sus distintas posiciones, seleccionen "mediante una distinción que permite representar las formas [...] como selección de un ámbito de un medium" (Luhmann 2007: 150).

Los mediums dejan de ser entonces solamente un conducto que une a las representaciones del sujeto con la realidad externa (Aristóteles 2006); como algo fijo, a-histórico e independiente de las condiciones existenciales de la vida humana (Gadamer 2012). De ser así, la totalidad de los objetos de las descripciones posibles quedaría separada de nuestro horizonte existencial de la experiencia (Habermas 2011), precisamente por "creer que las propiedades del observador no entran en las descripciones de sus observaciones" (Foerster, en Ceruti: 2000: 32). Los mediums, cuyo punto de arranque es el lenguaje, deben ser tratados desde un posicionamiento autológico; como estructuras que son capaces de atribuir significado al significado que se procesa a sí mismo (Schiltz 2002), a través de un observador que solo se puede observar estando-en-el-espacio-mundo desde sus propios esquemas de distinción (Von Foerster, en Robles 2012).

En relación con lo anterior, se puede entonces sostener que al observador le aparece "la realidad como una combinación entre potencialidad y facticidad" (Corsi 2012: 85), precisamente porque, con los mediums, se abren las condiciones para actuar en el mundo; ofrecen un horizonte de posibilidades que siempre pueden estar disponibles bajo la forma de actualidad. El observador deberá hacerse cargo de la complejidad de un mundo contingente, haciendo una distinción que se traduce en una "actualización de algo a través de la negación de lo demás. La negación que no significa anulación sino potenciación" (Luhmann 2000). Esta potencialidad equivale 
Territorio como medium: Discusión sobre rendimientos analíticos para las observaciones de la $\mid 149$ complejidad socio-espacial

a las posibilidades latentes que pueden actualizarse "en el momento que se experimenta, [en el momento en que se señala] una distinción y por ende una fijación determinada" (Luhmann 2007: 153). Ergo, los mediums, como condensaciones potenciales de sentido que perduran en el tiempo, permiten activar en cualquier momento las formas como conexiones comprensibles sobre nuestra existencia.

Por tal razón, sin los mediums, no solo no se tendría la capacidad de comprender el mundo, sino que tampoco se lo podría aprehender bajo la forma de accesibilidad (Luhmann 1998), porque, como logros evolutivos (Luhmann 2007), dejan de ser una mera condensación de recuerdos de las cosas que experimentamos, y vienen más bien a cumplir una función social: son el lado operativo de la forma (Corsi 2012), como un substratum de elementos que representan el potencial conectivo para la construcción de nuestras formas (Schiltz 2003). Se condensan en el tiempo para poder acceder al mundo, pues "dependemos del sentido como medium - el cual puede utilizarse solo selectivamente, solo construyendo formas, solo remitiéndose a algo distinto" (Luhmann 2007: 893).

A su vez, si el medium es una especie de substratum, entonces también sus conexiones para la construcción de formas se vuelven paradojales. Es decir, el medium posibilita que las formas sean observadas de manera distinta por aquellos que participan en la comunicación, pero también, dichas formas "reaparecen en sí mismas como lo distinguido" (Luhmann 2007: 38). En otras palabras, la forma se deposita en la comprensión que emerge en la comunicación, al momento en que los observadores participan en ella, pero la actualización, como "comunicación mediada", (Corsi 2012: 82), es observada de forma distinta por observadores, a pesar de referirse a un mismo medium;

La forma nunca es idéntica a sí misma (¿qué otra cosa podría significar tener una identidad?). Es estructuralmente más de lo que se puede indicar en la observación [...] Sin embargo, uno debe coincidir en que el aspecto estructural e indicativo de que la forma son uno y lo mismo; Después de todo, ¿no lo tomamos como un hecho de sentido común que dibujar la distinción e indicar uno de los lados separados, son dos aspectos de una misma operación indivisible? (Schiltz \& Verschraegen 2002: 60). ${ }^{2}$

2 Traducción del inglés responsabilidad de los autores de este artículo: "The form is never identical to itself (what else could 'having an identity' mean?), it is structurally more than it can indicate in the observation. It can never be 'present' to itself. Yet, one must concur that the structural and indicative aspect of the form are one and the same; after all, 
Los mediums, como condensaciones de sentido, se encargarán entonces de otorgarle vigencia a los contenidos para la actualización de formas, precisamente porque "cada uno de los significados tiene vigencia más allá de aquella unicidad que podrían exigir los acontecimientos históricos [en la que] cada palabra, incluso cada nombre, indica su posibilidad lingüística más allá del fenómeno particular que describe o denomina" (Koselleck, en Mariñez 2017: 113). Supone, en consecuencia, un fuerte potencial evolutivo para la construcción de diferencias de formas, las cuales pueden condensarse (repetirse) y eventualmente establecerse como un nuevo medium dentro de otro medium y así sucesivamente, como un regreso al infinito (Schiltz \& Verschraegen 2002).

Para finalizar con este apartado, es importante destacar que la actualización de las formas no solo se enfrenta a la complejidad temporal y objetual; también implica la posibilidad de la aceptación o rechazo de la comunicación. En otras palabras, con los mediums, el problema radica también en "la improbabilidad de que la comunicación sea aceptada" (Corsi 2012: 83), no solo por la comprensión, sino porque la oferta comunicativa de ego no es lo suficientemente creíble u óptima para que alter pueda aceptarla. Por ejemplo, a través del medium dinero, se puede adquirir una tarjeta Bip ${ }^{3}$, lo que significa aceptar la forma que permite el acceso a la red de transporte público del área Metropolitana de Santiago de Chile, pero también abre la posibilidad de rechazarla, evadiendo el pago del servicio en respuesta a la decepción que las fallas del sistema le provocan o por la estimación del alto el costo de las mismas. ${ }^{4}$ Tampoco basta con conformarse con una política pública por el hecho de escuchar el relato de la justicia y de la igualdad, sino también de poner sobre la mesa el hecho que persisten desigualdades, pobreza o exclusión social. El rechazo actualiza su lado negativo con la ayuda del medium, por ejemplo, a través de protestas, quejas, divorcios o evasiones. En síntesis, como condensaciones potenciales de sentido, involucra también las expectativas o decepciones que se construyen los participantes

\footnotetext{
did we not take it as a commonsensical fact that drawing the distinction and indicating one of the separated sides were two aspects of one and the same indivisible operation?" (Schiltz \& Verschraegen 2002: 60).

3 Tarjeta bip es un medio de pago del sistema de transportes del Transantiago de Chile, tanto para buses como para el Metro. incluye buses y Metro.

4 El índice de evasión del Transantiago en el primer trimestre 2017 corresponde a un 31,4\%, en el primer semestre del 2017, según el Programa Nacional de Fiscalización del Gobierno de Chile. Para mayor información: http://www.fiscalizacion.cl/informes-trimestrales/
} 
en la comunicación por medio de una oferta comunicativa llevada por los medium.

Habiendo aclarado los aspectos generales de la distinción medium/forma, cabe ahora aplicarla al 'territorio', en pos de poder entender la manera en que lo socio-espacial podría ser considerado como un medium para la actualización de una multiplicidad de formas.

\section{EL MEDIUM TERRITORIO Y SUS MÚLTIPLES FORMAS}

Si buscamos comprender al territorio como un medium, es precisamente porque, a lo largo de la historia, este concepto ha venido cumpliendo con una función social: condensar expectativas para que los múltiples observadores puedan tematizarlo y así construir o acceder a formas sociales cuando hacen descripción de sus observaciones. Por ejemplo, con la emergencia de los Estados separados de la religión, a inicios de la modernidad, se empieza a comunicar sobre el territorio como una forma de organización política delimitada territorialmente, con cargos públicos y rigiéndose por la constitución y sus leyes para proteger los intereses personales de los individuos (Locke 2005; Hobbes 2010).

En relación con este logro evolutivo, las observaciones presentes sobre el territorio pueden vincularse con los derechos humanos, siendo éstas últimas producto de "construcciones y conquistas político-jurídicas que responden de un lado a las demandas sociales [...] y de otro, a la demanda de inclusión de personas y grupos" (Neves 2004: 143). Su semántica promueve la protección y asignación de deberes y derechos en territorios nacionales e internacionales; su marco normativo asegura "su reconocimiento y aplicación universales y efectivos tanto entre los pueblos de los Estados Miembros como entre los territorios colocados bajo su jurisdicción" (ONU 1948: 2). Hoy en día, es posible también dar cuenta de una expansión de los derechos civiles, políticos y sociales que se traducen, por ejemplo, en reivindicaciones de minorías culturales (Kymlicka 1996), en la emergencia organizaciones no-gubernamentales globales que buscan generar impacto en la opinión pública sobre los problemas vinculados a la globalización (Giménez 2016) o en nuevas formas de gobernanza en contextos transnacionales (Kjaer 2017).

Con las adquisiciones evolutivas ejemplificadas anteriormente se parte entonces del supuesto que, en la actualidad, se han complejizado las obser- 
vaciones sobre el territorio, producto de los cambios sociales que vivencia la sociedad, o fruto justamente de una simultaneidad de cambios que se diversifican adentro de los límites de los sistemas locales o globales (Luhmann 1997). En este sentido, el tener "una nacionalidad frente a la particularidad irremediable de sus manifestaciones concretas" (Smith 1983: 22) no es suficiente para referirse al territorio, pues existen múltiples formas o procesos diferenciados que trascienden los límites geográficos. Es decir;

La diferenciación territorial [ya no solo se refiere] a la construcción de un espacio limitado y demarcado de otros espacios sociales sobre la base de fronteras geográficas, [también hay] diferenciación funcional, que se caracteriza por el principio de la igualdad de diferentes esferas de la sociedad vinculadas a diferentes funciones de reproducción material y normativa en relación con áreas como la economía, la ciencia, la religión, etc." (Kjaer 2017: 7). ${ }^{5}$

En este sentido, los territorios deben ser pensados desde la diferenciación funcional, ya que las fronteras "no son creadas ni por condiciones de la vida semejantes, ni por normas compartidas, sino por la simultaneidad de lo diferente" (Nassehi 2011: 10); lo que se traduce, en otras palabras, en la multiplicidad de comunicaciones diferenciadas que operan de forma simultánea. Esto significa dar cuenta que, no solo todo es posible, sino que ello es posible de diferentes maneras; un problema -en nuestro caso el territorio- puede ser tratado políticamente, económicamente, judicialmente, educativamente, religiosamente y por supuesto científicamente (Schirmer \& Hadamek 2007).

Frente a esta diferenciación funcional que caracteriza hoy en día a la sociedad moderna, las observaciones de la complejidad socioespacial se deben mirar de otra manera. Por tal razón, se presenta a continuación la forma en que el territorio puede ser abordado y así dar cuenta de cómo los observadores construyen sus expectativas sobre lo que observan cuando se tematiza al territorio en una simultaneidad de comunicaciones diferenciadas.

\subsection{TEMATIZACIÓN DEL TERRITORIO: SU DIMENSIÓN OBJETUAL}

Este medium despliega sus formas cuando los observadores buscan dar a conocer 'algo' sobre el territorio. Tiene que ver, en otras palabras, con lo

\footnotetext{
5 Traducción del inglés responsabilidad de los autores de este artículo: "Territorial differentiation implies the construction of a limited and coherent social space which is demarcated from other social spaces on the basis of boundaries which symbolically refer to geographical borders" (Kjaer 2017: 7).
} 
que objetualmente se informa sobre el territorio, por ejemplo, a través de los medios de masas, en la rendición de cuentas públicas de las municipalidades, en la articulación de programas por parte de las organizaciones no gubernamentales, en los acuerdos que puede llegar una junta de vecinos en torno a un problema en específico, en poner sobre la mesa un acto indignante en materia de derechos sociales con la ayuda de los movimientos de protestas, o hasta en una propuesta conceptual para estudiar al territorio en las ciencias sociales. Bajo sus propias lógicas de observación, se tematiza al territorio para describir algún acontecimiento o bien para referirse a algún problema en específico. Es decir, el medium territorio no solo se actualiza como tema comunicacional para referirse al día del patrimonio, al día de la independencia, al día nacional de los pueblos indígenas o a la victoria de un equipo en una copa mundial. También sirve para referirse a los problemas que irritan a los individuos con sus instituciones, las cuales son observadas de forma distinta por quien procesa la descripción de sus observaciones.

Recordemos que nos encontramos bajo un posicionamiento autológico y, por lo tanto, no hay una observación común, única o mejor, sino múltiples observaciones diversas despendiendo de sus posiciones y sistemas referenciales (Arnold 2010). Por ejemplo, un problema medioambiental en una comuna periférica es comunicado de forma distinta por un programa de televisión que por un movimiento de protesta. Si las noticias o los reportajes construyen una realidad centrada en hacer informable lo no informable a través de la sorpresa, lo anecdótico o lo espectacular (Luhmann 2007), para el movimiento de protesta, el problema ambiental puede ser expresado en nombre de la sociedad, ya que participará en la comunicación de la sociedad como afectado en nombre de los afectados (Robles 2013) y no en nombre del entretenimiento. Otro ejemplo lo podemos observar cuando un periodista entrevista a un individuo que vive en un territorio "vulnerable”. La finalidad de esta entrevista será completamente distinta a la de un profesional del área social que trabaja en una municipalidad y que interviene en torno a su privación material de bienes y servicios. Por último, no es igual observar lo que comunican las ciencias sociales que buscan observar fenómenos sociales, como la desigualdad territorial, a lo comunicado por una empresa que se considera socialmente responsable y que busca mantener una imagen como tal con la sociedad -sin perder su lógica de costo-beneficio. 
Desde su dimensión objetual, el territorio es 'tema' y puede tomar múltiples formas desde la posición del observador y las referencias a las cuales alude. Basta ver la forma también en que los territorios quedan tematizados para generar programas interinstitucionales, donde ya no se pone el foco solo en lo nacional sino también en la gobernanza global (Wilkinson \& Hughes 2002); la manera en que los organismos internacionales tematizan al territorio a través de informes sobre los derechos humanos o índices de corrupción, desigualdad, gastos en la educación, salud, vivienda, etc., y así comparar los niveles de desarrollo en los países en estas materias. Tampoco se puede olvidar la manera en que la geopolítica hace uso de ese medium para llegar a acuerdos estratégicos con países que se encuentran en conflicto (Graham 2008).

Por otra parte, las observaciones no son solamente políticas o económicas. El medium también puede ser el deporte, por ejemplo, cuando hay mundiales de futbol u olimpiadas, en donde se actualizan observaciones nacionales a través de los equipos o deportistas que representan a sus países con la ayuda de las redes sociales o los medios de masas. Si, con el deporte, "se pueden escenificar rituales antiguos para recrear experiencias religiosas o conmemorar efemérides nacionales; o se pueden musealizar prácticas para hacerlas aparecer como autenticidad cultural y atraer turistas para construir la ficción de multiculturalidad" (Crego, en Mascareño 2012: 70), entonces el medium territorio contribuye a ello. También desde el turismo se puede hacer uso de este medium para describir delimitaciones espaciales e indicar sus atractivos, a través de ferias costumbristas en pequeñas localidades, zonas naturales, ecológicas, arqueológicas o históricas, así como sus problemas para llevar a cabo dichas intensiones. Así, podemos nombrar una infinidad de sistemas u observadores que refieren al medium territorio, para procesar y actualizar una diversidad de formas.

Desde su dimensión objetual, el rendimiento del territorio no es menor, pues pone el foco justamente en lo que se conoce en el mundo sobre él. Es decir, si lo familiar es lo que se nos hace conocido en el mundo de nuestra existencia (Luhmann 1996), es porque 'el territorio' y sus múltiples formas también forman parte de lo familiar. La construcción de formas dependerá de la familiaridad que se tenga sobre el territorio, lo que es también condición para poder abrirse a la pluralidad de mundos contingentes. En este sentido, el pasado condiciona la posibilidad de conocer las diversas formas que se despliegan sobre el territorio, también para saber uno mismo 
a 'transitar' con los riesgos en las decisiones que se deben tomar cuando se hace referencia a posiciones, límites y distancia.

\subsection{PRobabilidad DE COORDINAR EXPECTATIVAS EN REFERENCIA AL 'TERRITORIO': SU DIMENSIÓN SOCIAL}

En segundo lugar, es interesante observar cómo es posible que la coordinación de expectativas se efectúe cuando se actualiza algún tema referente al territorio. En otras palabras, si la dimensión objetual del medium territorio nos da a conocer las descripciones sobre el territorio desde diferentes perspectivas, pues ahora habría que ver cómo es posible que los participantes acepten o rechacen dicha comunicación desde sus posiciones como observadores. Como mencionamos anteriormente, el medium permite transformar lo improbable en probable al encontrarse alter y ego en un evento comunicacional. Por lo tanto, con la ayuda del medium territorio, éstos coordinan u orientan las motivaciones en el mundo que ellos co-experimentan en un contexto determinado. Esto implica que la posibilidad de aceptar una oferta comunicativa referente al territorio no dependa de una causalidad preestablecida o de una condición normativa universalista para que el consenso sea posible (Habermas 2011). La posibilidad del acuerdo depende de una evaluación reflexiva acerca de su capacidad para solucionar problemas, lo cual puede ser equivalentemente funcional a otras soluciones disponibles más allá de un fundamento ético (Mariñez \& Pérez-Solari 2017). La pregunta entonces es cómo, al tematizar el territorio, se abren las condiciones de posibilidad para que los afectados sean gatillados para aceptar o el rechazar la oferta para la solución a un problema, en el entendido de que siempre se puede decidir de otra manera.

Con el medium territorio, los participantes estarán en condiciones de seleccionar (para actualizar una forma) una oferta comunicativa, viéndose al mismo tiempo enfrentados a su misma complejidad: a una coacción de selección que se traduce en actualizar una alternativa, pero esta selección, a su vez, implica la negación de un horizonte de posibilidades que pudieron ser seleccionadas de otro modo. En consecuencia, el medium territorio ayuda a enfrentarse a la doble contingencia, pues, como estructura de selectividad, nos abre las condiciones para probabilizar la comunicación; para saber evaluar qué opción puede ser la más viable cuando se tematiza territorio. Por eso, la probabilidad de que una oferta comunicativa sea aceptada dependerá, 
por ejemplo, si la política pública logra hacerle comprender a los afectados que su territorio tendrá mejoras significativas en materia de bienes y servicios o en materia de derechos humanos, igualdad de género, raza, religión, entre otros. Implica que, a través del medium, se gatille una motivación por parte de la comunidad cuando se comprenden sus formas para la aceptación o rechazo de las mismas.

Un último ejemplo interesante al respecto puede ser el de un espacio baldío de propiedad pública en un barrio de clase media que puede ser identificado y comunicado como un lugar propicio para la construcción de viviendas sociales. Los actuales residentes pueden argumentar su rechazo a la idea, indicando que la instalación de tales edificaciones disminuiría la plusvalía de sus propiedades; mientras que los potenciales postulantes a acceder a esas viviendas comunicarían la urgencia de acceder a dichos terrenos apelando a su necesidad de un lugar donde habitar con sus familias. Ante ello, la municipalidad puede observar este lugar y ofertar como posible solución a la complejidad sobre el territorio, gestionar la demanda de vivienda del comité ante el ministerio respectivo y acompañar el proceso de postulación a las mismas. Ante las comunicaciones previas, se produce doble contingencia en relación al territorio. La posibilidad de acuerdo dependerá de una evaluación reflexiva —en este caso de los actuales residentes y el comité de vivienda- relativa al posible éxito de las posibilidades y planes sobre el territorio para solucionar o no los problemas de la comunidad que lo habita.

En síntesis, la dimensión social del territorio se hace relevante, ya que se presta atención al modo en que alter le comunica a ego que puede haber alguna solución cuando 'el territorio' se convierte en un problema. Se hace posible entonces mirar a los observadores y ver hasta qué punto, con dicho medium, se probabiliza una oferta comunicativa, con los riesgos que ello implica. En este punto, aparece un problema de confianza, pues ego tendrá que arriesgarse a aceptar la apuesta de alter y de confiar en que aquella promesa se cumpla en un presente. En otras palabras, al saber que hay una cantidad de conocimiento técnico que las personas no saben procesar en sus vivencias -como, por ejemplo, cuando una política pública o un programa social ofrece enseñar a sus usuarios a emprender un negocio-, la posibilidad de confiar se transforma en un riesgo: uno puede encontrarse con que, al hacerse presente la oferta, sea fruto de una decepción (Luhmann 1996). Pero dicha decepción se nos hará también familiar en un nuevo contexto y, frente a la improbabilidad de coordinar expectativas sobre un 
problema territorial, podremos por lo menos estar alertas y prestar mayor atención a las expectativas de alter (Luhmann 2013).

\subsection{UN 'ANTES' Y UN 'DESPUÉS' DEL TERRITORIO: SU DIMENSIÓN TEMPORAL}

Por último, debemos abordar el territorio desde su dimensión temporal. Se debe considerar que "ni los conceptos ni el mundo pueden ser tratados como una norma fija" (Luhmann, en Lewkow 1: 2015), razón por la que debemos hacer alusión a los cambios a los que se ve enfrentado constantemente el medium territorio a través del tiempo. Al referirse a la dimensión temporal, se hace alusión a la articulación de horizontes del pasado y del futuro (Corsi et al.1996), los cuales se configuran siempre en un tiempo presente, por tanto, dicha construcción temporal, no se encuentra exenta de complejidad. Dicha complejidad, en la dimensión temporal, presupone dos modos distintos de determinar el tiempo presente, los cuales son posibles solo en la actualidad.

Por una parte, tenemos la concepción del tiempo puntualizado como un evento, en el que el futuro se transforma continuamente en pasado (medible y se pierde constantemente) y, por otro lado, dicha puntualidad puede ser observada únicamente sobre la base de un presente duradero "...y que garantiza la posibilidad de la reversibilidad" (Corsi et al.1996). Esta distinción entre puntualidad y duración hace posibles un futuro y un pasado, puesto que, con base en la irreversibilidad (o la sola duración), no serían posibles las proyecciones y el estudio del tiempo para un sistema. Valiéndonos de la distinción puntualidad/duración podemos distinguir estructuras y procesos ocurridos o a ocurrir dentro del medium territorio.

Para el estudio de la dimensión temporal de la complejidad socioespacial desde la distinción medium/forma, resulta relevante no solo observar lo que indican la multiplicidad de observadores cuando se refieren al territorio, sino también observar procesos diferenciados que operan de forma simultánea, precisamente por la complejidad misma de las formas mediadas. Por lo tanto, el tiempo es una interpretación de la realidad con base en las diferencias existentes entre pasado y futuro de los observadores que observan, ya que ellos pueden 
Constatar similitudes, reconocer repeticiones, distinguir entre antes y después (para encontrar, por ejemplo, distancias temporales o para designar efectos a las causas), pero solo lo puede hacer con ayuda de las diferenciaciones que utiliza y solo bajo la condición estricta de la simultaneidad de sus propias operaciones de observación, con todo lo que acontece. (Luhmann 2006: 45).

Esta posibilidad de observar procesos se ve relflejada en instituciones que tienen la función de generalizar expectativas en la sociedad. Su estabilidad dinámica o la posibilidad de que puedan operar en el tiempo depende de que sus decisiones sean lo suficientemente efectivas para la solución de problemas; para que sus acciones duren para futuros eventos (Luhmann 1998). Desde el medium territorio, una entidad pública, por ejemplo, puede actualizar una multiplicidad de formas con el propósito de ofrecer mejores posibilidades a los usuarios de una comunidad. Pero si pasa lo contrario, se corre el riesgo de que se generalicen las decepciones, ya que las soluciones no son lo suficientemente efectivas para anticiparse a las necesidades de los afectados. Se corre el riesgo, en consecuencia, de que las formas decisionales no puedan persistir en el tiempo, ya que lo que se da a conocer son más bien las decepciones, puesto que las soluciones no fueron efectivas.

En este sentido, la comunicación construye expectativas entre aquellos observadores que participan de las observaciones del territorio, entendiendo que dichas expectativas serán la anticipación de un evento o consecuencia futura (Escoriza 1985). Este sería el caso, por ejemplo, de los procesos de erradicación que se llevaron a cabo en la década de los ochentas, cuando se trasladaron masivamente a familias a sectores periféricos de baja plusvalía con el fin de otorgarles una vivienda social que resolviera su problema habitacional. En este sentido, la efectividad de esta forma no habría respondido a las expectativas de los grupos erradicados, generando decepciones ante la ausencia o precariedad de otras formas complementarias a la vivienda, como serían equipamiento comunitario y acceso a servicios de primera necesidad.

Esta dimensión temporal resulta entonces clave para observar fenómenos socio-espaciales. Sus rendimientos pueden dar cuenta de la multiplicidad de universos que construyen los observadores en sus múltiples temporalidades cuando realizan una distinción respecto de lo que indica un programa social, una unidad vecinal, una empresa, un municipio, un club de adulto mayores, una cámara de comercio y turismo, etc. Observar fenómenos complejos desde esta mirada representa un desafío importante, pues los 
observadores describen el territorio sin correspondencia punto por punto entre sus observaciones, sino más bien simultaneidad de acontecimientos diversos y diferenciados sobre un tema que temporalmente se condensa y actualiza como forma. No obstante, paradojalmente, se ofrecen innumerables posibilidades de conexión con nuevas miradas sobre un mismo contenido referido al territorio.

\section{CONCLUSIONES}

El análisis anterior buscamos desarrollar una propuesta conceptual sobre el territorio desde un posicionamiento sistémico constructivista, tratando de ver de qué manera el territorio puede ser considerado un medium para la construcción de formas al participar este en la comunicación (social). Observamos también cómo pueden construirse expectativas (tiempo) cuando se tematizan posiciones, distancias, límites geográficos, etc. (objetual). Observamos, en este sentido, que el medium territorio implica una estructura de selectividad de sentido que se actualiza en múltiples presentes, en una pluri-diversidad de formas para sistemas como la política, la economía, la ciencia, la educación, la vivienda, la salud, la agricultura, la seguridad pública, el derecho, etc. Las instituciones, por ejemplo, traducen comunicacionalmente al territorio bajo sus propios lentes de observación para hacer comprender a sus destinatarios sus intenciones, con base en la solución de los problemas referentes al territorio.

Los rendimientos explicativos de lo anterior no son menores, pues, desde una mirada de la complejidad, se reconoce que los observadores crean su propio universo por medio de una distinción en la que entran las descripciones de sus observaciones (Foerster, en Ceruti 2000: 32). En otras palabras, las descripciones de los observadores sobre el territorio no se centran en demostrar qué hay en él -para buscar algo que esté determinado apriorísticamente o de forma causal. El medium territorio solo puede ser observado autorreferencialmente mediante distinciones de sistemas observadores que producen información sobre él y que agregan contenido a sus descripciones a partir de sus propias lógicas para tematizar luego al territorio como forma para sus comunicaciones.

Cabe preguntarse si esta propuesta conceptual presenta también rendimientos para analizar los procesos de inclusión y exclusión social. Puesto que la complejidad refiere a que siempre existen más posibilidades de las 
que se pueden seleccionar (Luhmann 1998), en la sociedad existe una diversidad de inclusiones y de exclusiones que se actualizan cuando las personas participan o no en la comunicación (Luhmann 1998). Por lo tanto, "su complejidad debe ser reconfigurada para captar la complejidad de las relaciones que ella misma contiene cuando la sociedad moderna se diferencia funcional y contextualmente, de forma que inclusión/exclusión se entrecruzan de modos paradójicos" (Mascareño 2014: 13). Esto implica tener en cuenta a dichas paradojas para observar observaciones socio-espaciales, de modo de no caer en principios explicativos que ontologizan a las personas 'en' un espacio o cuando las subclasifican en un territorio como vulnerables, pobres o excluidos.

En otras palabras, los estudios sobre exclusión social territorial centrados en la condición precaria de los individuos resultan insuficientes para observar inclusiones y exclusiones múltiples (Arnold 2012). Por tal razón, se justifica el desarrollo de plataformas de observación para fenómenos complejos y emergentes relativos a la inclusión y exclusión 'sobre' el territorio. Dicho trabajo a futuro podría apoyarse en una dimensión teórica que tenga por objeto observar observaciones sobre el territorio relativas a la inclusión y exclusión social como formas que se actualizan cuando las personas participan en la comunicación. En otras palabras, observar el 'peso' del medio territorial en términos de inclusión y exclusión social, identificar sus formas comunicacionales y sus efectos de inclusión o exclusión; cuando la política pública, por ejemplo, tematiza comunicacionalmente al territorio produciendo efectos de inclusión o de exclusión, los que son totalmente distintos a los que surgen en los campos laborales, familiares o en los establecimientos escolares.

Finalmente, esta perspectiva puede conducir a otra línea interesante de explorar, a saber, cómo se tematiza el territorio como riesgo, cuando las comunicaciones sobre este producen efectos no deseados para los afectados o para el operar mismo del que cumple el rol de decidor (Luhmann 2012). Esto implica agudizar la mirada sobre decisiones que tematizan el territorio y que no solo no logran solucionar los problemas de los afectados, sino que despliegan nuevas formas de inclusión en la exclusión o de exclusión en la inclusión (Robles 2005), dependiendo esto útlimo del modo en que estos afectados, en un horizonte de posibilidades, logran coordinarse entre ellos (redes de apoyo) o con las instituciones que entregan soluciones a sus problemas específicos.M 
Territorio como medium: Discusión sobre rendimientos analíticos para las observaciones de la $\mid 161$ complejidad socio-espacial

\section{REFERENCIAS}

Adorno, T. (2008). Sobre la lógica de las ciencias sociales. In T. Adorno, K. Popper, R. Dahrendorf, \& J. Habermas (Eds.), La lógica de las ciencias sociales (pp. 13-22). México DF: Colofón.

Arnold, M. (2010). Constructivismo sociopoiético. Mad, 23, 1-8.

Arlnold, M. (2014). Imágenes de la complejidad. Diferenciación, integración y exclusión social. In H. Cadenas, A. Mascareño, \& A. Urquiza (Eds), Niklas Lubmann y el legado universalista de su teoría. Aportes para el análisis de la complejidad social contemporánea (pp. 49-56). Santiago de Chile: RIL Editores.

Aristóteles. (2006). Ética Nicómaco. México DF: Tomo I.

Allen, P. (2012). Cities and Regions as Self-organizing Systems: Models of Complexity. Abingdon: Routledge.

Andrade, R., Cadenas, E., Pachano, E., Pereira, L., \& Torres, A. (2001). El Paradigma complejo. Cinta de Moebio, 14, 236-279.

Angell K. (2016). A Forward-Looking Justification of Territorial Rights. Political Studies, 65(1), 231-247.

Anguiano E. (2008). Chiapas: territorio de inmigración, emigración y tránsito migratorio. Papeles de población, 14(56), 215-232.

Arapoglou, V. (2012) Diversity, Inequality and Urban Change. European Urban and Regional Studies, 19 (3), 223 - 237.

Awan, N. \& Langley, P. (2013). Mapping Migrant Territories as Topological Deformations of Space. Space and Culture, 16(2), 229-245

Boisier, S. (2004). Desarrollo territorial y descentralización. El desarrollo en el lugar y en las manos de la gente. EURE, 90(3), 27-40.

Boisier, S. (1997). El vuelo de una cometa. Una metáfora para una teoría del desarrollo territorial. EURE, 23(69), 1-38.

Boschken, H. (2000). Urban Spatial form and Policy Outcomes in Public Agencies. Urban Affairs Review, 36(1), 61-83.

Bourdieu, P. (2008). El sentido práctico. Madrid: Siglo XXI.

Bourdieu, P. (1997). Capital cultural, escuela y espacio social. México DF: Siglo XXI.

Burger M. \& Meijers, J. (2012). Form Follows Function? Linking Morphological and Functional Polycentricity. Urban Studies, 49(5), 1127-1149.

Cannarella, C \& Piccioni, V. (2007). Innovation Diffusion and Territorial Inertia. International Journal of Rural Management, 3(2), 181-211.

Caquimbo, S. (2009). La calidad del espacio público en la construcción del paisaje urbano. En busca de un hábitat equitativo. INVI, 23(62), 75- 97.

Centro Latinoamericano para el Desarrollo Rural. (2013). Informe Latinoamericano Pobreza y Desigualdad: Empleo de Calidad y Territorio. Consultado el 10 de enero 2017, desde http://rimisp.org/wp-content/files mf/1489673127Sintesis2013.pdf

Collyer, M. \& King, R. (2014). Producing Transnational Space: International Migration and the Extra-Territorial Reach of State Power. Progress in Human Geography, 39(2), 185-204.

Connell, R. (2013) Using Southern Theory: Decolonizing Social Thought in Theory, Research and Application. Planning Theory, 13(2), 210-223.

Corsi, G., Esposito, E., \& Baraldi, C. (1996). Glosario sobre la teoría social de Niklas Lubmann. México DF: Anthropos. 
Corsi, G. (2014). 'Hacer lo mismo de otro modo'. Problemas de la dirección directriz medio/forma. In H. Cadenas., A. Mascareño., \& A. Urquiza (Eds). Niklas Lubmann y el legado universalista de su teoría. Aportes para el análisis de la complejidad social contemporánea (pp. 81-106). Santiago de Chile: RIL Editores.

Cortez, M. \& Matus, T. (Eds) (2016). Innovación social efectiva: Una propuesta de evaluación para programas sociales. Santiago de Chile: Editorial Libros de Mentira.

Ceruti, M. (1998). El mito de la omnisciencia y el ojo del observador. In P. Watzlawick \& P. Krieg (Eds.), El ojo del observador (pp. 32-59). Barcelona: Gedisa.

Curtis, S. \& Riva, M. (2009). Health Geographies I: Complexity Theory and Human Health. Progress in Human Geography, 34(2), 215-223.

Damjanov, K. (2015). The Matter of Media in Outer Space: Technologies of Cosmobiopolitics. Environment and Planning D: Society and Space, 33(5), 889-906.

Escoriza, N. (1985). Motivación y aprendizaje. In J. Peralta, Rol de las expectativas en el juicio de satisfacción y calidad percibida del servicio. Limite, Revista de filosofía y psicología, 1(14), 202-208.

Ezcurra, R. (2014). Government Quality and Spatial Inequality: A Cross-Country Analysis. Environment and Planning A, 46(7), 1732-1753.

Foerster, H. von (2014). The Beginning of Heaven and Earth Has No Name. Seven Days with SecondOrder Cybernetics. New York: Fordham University Press.

Foucault, M. (2006). Seguridad, territorio, población. Buenos Aires: Fondo de Cultura Económica.

Featherstone, D. (2013). Space, Subalternity, and Critique, or Which Subaltern Studies for Which Geography? Cultural geographies, 24(2), 341 - 346.

Fixari, D. \& Pallez, F. (2016). A Public Strategy under Construction? Coordination and Performance in Territorial Innovation Systems. International Review of Administrative Sciences, 82(3), 418-434.

Gadamer, H. (2012). El giro hermenéutico. Madrid: Cátedra.

Gibler, D., Hutchison M., \& Miller S. (2012). Individual Identity Attachments and International Conflict. The Importance of Territorial Threat. Comparative Political Studies, 45(12), $1655-1683$.

Goffman, E. (1967). Ritual de la interacción. Ensayo sobre el comportamiento cara a cara. Buenos Aires: Tiempo Contemporáneo.

Giménez, G. (1996). Territorio y cultura. Estudios sobre las Culturas Contemporáneas, 2(4), 9-30.

Giménez, G. (2001). Cultura, territorio y migraciones. Aproximaciones teóricas. Alteridades, $11(22), 5-14$.

Giménez, G. (2016). Estudio sobre la cultura y las identidades sociales. Guadalajara: Intersecciones.

Guevara T. (2015). Abordajes teóricos sobre las transformaciones sociales, económicas y territoriales en las ciudades latinoamericanas contemporáneas. EURE, 41(124), 5-24.

Habermas, J. (2011). Verdad y justificación. Madrid: Trotta.

Hensel, P. \& McLaughlin M. (2016). From Territorial Claims to Identity Claims: The Issue Correlates of War (ICOW). Conflict Management and Peace Science, 34(2), 126-140.

Hobbes, T (2010). Elementos filosóficos del ciudadano. Buenos Aires: Hydra.

Holsrsen S. (2013). Spatial Planning as Condensation of Social Relations: A Dialectical Approach. Planning Theory, 14(1), 5 - 22.

Kymlicka W. (1996). Ciudadanía multicultural: Una teoría liberal de los derechos de las minorías. Barcelona: Paidós.

Kirat, T. \& Lung, Y. (1999). Innovation and Proximity: Territories as Loci of Collective Learning Processes. European Urban and Regional Studies, 6(1), 27-38. 
Territorio como medium: Discusión sobre rendimientos analíticos para las observaciones de la 163 complejidad socio-espacial

Kjaer, P. (2017). Why Justification? The Structure of Public Power in Transnational Contexts. Transnational Legal Theory, 8(1), 8-21.

Kollmann, M. (2005). Una revisión de los conceptos de “territorios equilibrados" y "región". Procesos de construcción y descontrucción. Theomai, 11(1), 1-12.

La Porte, T. (1976). Organized Social Complexity: Challenge to Politics and Policy. New Jersey: Princeton University Press.

Leydesdorff, L. \& Deakin, M. (2011). The Triple-Helix Model of Smart Cities: A NeoEvolutionary Perspective. Journal of Urban Technology, 18(2), 53-63.

Leal, J. (2002). Segregación social y mercados de vivienda en las grandes ciudades. Revista Española de Sociología, 2, 59-75.

Lewkow, L. (2015). Cuatro tesis sobre el concepto de sentido en la teoría de sistemas de Niklas Luhmann. Sistemas Sociales, Consultado el 13 de marzo 2017, desde http://sistemassociales.com/cuatro-tesis-sobre-el-concepto-de-sentido-en-la-teoria-desistemas-de-niklas-luhmann-2/

Lindón, A. (2007). El constructivismo Geográfico y las Aproximaciones Cualitativas. Revista de Geografía Norte Grande, 37, 5-21.

Locke J. (2005). Ensayo sobre el entendimiento humano. México DF: Fondo de Cultura Económica.

Luhmann, N. (1996). Confianza. México DF: Anthropos.

Luhmann, N. (1997). Globalization or World Society: How to Conceive of Modern Society? International Review of Sociology, 7(1), 67-79.

Luhmann, N. (1998). Sistemas sociales. Lineamientos para una teoría general. México DF: Anthropos.

Luhmann, N. (2006). Sociología del riesgo. México DF: Universidad Iberoamericana.

Luhmann, N. (2007). La sociedad de la sociedad. México DF: Herder.

Luhmann, N. (2013). La moral de la sociedad. Madrid: Trotta.

Luukkonen, J. (2014). Planning in Europe for 'EU'rope: Spatial Planning as a Political Technology of Territory. Planning Theory, 14(2), 174-194.

Mace, A. (2015). Spatial capital as a tool for planning practice. Planning Theory, 16(2), 119-132.

Mac-Clure, O., Barozet, E., \& Maturana, V. (2014). Desigualdad, clase media y territorio en Chile: ¿clase media global o múltiples mesocracias según territorios? EURE, 40(121), 163183.

Madaniour A., Weck S. (2015). Social Exclusion and Poverty in Europe: Territorial Patterns. Local Economy, 30(7), 715-720.

Marull, J., Pino, J., \& Tello, E. (2008). The Loss of Territorial Efficiency: An Ecological Analysis of Land-Use Changes in Western Mediterranean Agriculture. Global Environment, 2, 112-150.

Mariñez, C. (2017). Posibilidad e imposibilidad interpretativa del Pragmatismo Formal para el estudio de la confianza en los actos de habla. Tesis de Doctorado en Filosofía mención Moral y Política. Universidad de Chile, Santiago, Chile.

Mariñez, C. \& Pérez-Solari, F. (2017). La ética de la confianza en una sociedad compleja. Una mirada sistémica al caso institucional. In F. Mariñez (Ed), Democracia, colaboración y compromiso cívico. Guadalajara: Colegio de Jalisco.

Mascareño, A. \& Büscher C. (2011). Sociología del territorio. Labor interdisciplinaria de Desarrollo Regional. Lider, 18(13), 25-52.

Mascareño, A. (2012). Auto-caotización en la sociedad mundial. Lineamientos para una teoría de la diferenciación contextual. Cinta moebio, 44, 61-105.

Mascareño, A. (2014). Diferenciación, inclusión/exclusión y cohesión en la sociedad moderna. Revista del Centro de Investigación Social de un Techo para Chile, 17, 8-25. 
Matus T. (Ed). (2009). La reforma municipal en la mira: Identificando los municipios prioritarios en la Región Metropolitana. Complejidad comunal v/s condiciones para la calidad de la gestión municipal. Santiago de Chile: Expansiva.

MacCallum, D., Moulaert, F, Hiller, J. \& Haddoc, S. (Eds). (2008). Social Innovation and Territorial Development, Ashgate: Farnham.

Morín, E. (1995). La relación ántropo-bio-cósmica. Gazeta de Antropología. Consultado el 10 de diciembre 2016, desde http://www.ugr.es/ pwlac/G11_01Edgar_Morin.html

Naciones Unidas. (1948). Declaración Universal de Derechos Humanos. Consultado el 12 de abril 2017, desde http://www.un.org/es/universal-declaration-human-rights/

Nassehi, A. (2011). La teoría de la diferenciación funcional en el horizonte de sus críticas. Mad, 24, 1-29.

Neves, M. (2004). La fuerza simbólica de los derechos humanos. Doxa, 27, 143-180.

Oliver, R. (1997). Satisfaccion: A Behavorial Perspective on the Consumer. New York. Routledge.

O'Sullivan D., Manson S., Messina J., \& Crawford T. (2006). Space, Place, and Complexity Science. Environment and Planning, 38, 611-617.

Oort, F. van, Burger, M., \& Raspe, O. (2010). On the Economic Foundation of the Urban Network Paradigm: Spatial Integration, Functional Integration and Economic Complementaries within the Dutch Randstad. Urban Studies, 47, 725-748.

Parkinson, R. (2013). How is Space Public? Implications for Spatial Policy and Democracy. Environment and Planning C: Government and Policy, 31(4), 682-699.

Pfeilstetter, R. (2011). El territorio como sistema social autopoiético: pensando en alternativas teóricas al "espacio administrativo" ya la "comunidad local". Periferia: revista de recerca $i$ formació en antropologia, 14, 1-17.

Piang, L. (2015). Overlapping Territorial Claims and Ethnic Conflict in Manipur. South Asia Research, 35(2), $158-176$.

Pintos, J.L. (1995). Los imaginarios sociales: la nueva construcción de la realidad social. Salamanca: Sal Terrae.

Pizaña, H. (2015). Transformaciones Socioterritoriales en el espacio rural: análisis desde una observación sistémica en el marco del proyecto ciudades rurales sustentables implementado en Chiapas, México. Tesis de Magíster Análisis Sistémico aplicado a la Sociedad, Universidad de Chile, Santiago, Chile.

Robles, F. (2012). Dificultades y paradojas de la observación de segundo orden: Reflexiones en torno al cálculo de la forma. Mad, 27, 15-33.

Robles, F. (Inédito). La notabilidad y los riesgos de los movimientos sociales en el contexto chileno. El caso particular del movimiento estudiantil de 2011.

Roitman, S. (2003). Barrios cerrados y segregación social urbana. Scripta Nova, 146(118).

Romero, H. \& Vásquez, A. (2005). La comodificación de los territorios urbanizables y la degradación ambiental en Santiago de Chile. Scripta Nova, 194(68).

Sabatini, F. (2003). La segregación social del espacio en las ciudades de América Latina. Santiago de Chile: Banco Interamericano de Desarrollo.

Santos, M. (2000). La naturaleza del espacio: técnica y tiempo, razón y emoción. Ariel: Madrid.

Sassone, S. (2007). Migración, territorio e identidad cultural: Construcción de "lugares bolivianos" en la Ciudad de Buenos Aires. Población de Buenos Aires, 4(6), 9- 28.

Sarma, B. (2016). Space and Territoriality. International Studies. 50(1-2), 92-108.

Schiltz M. \& Verschraegen G. (2002) Spencer-Brown, Luhmann and Autology. Cybernetics \& Human Knowing, 9(3-4), 55-78.

Schiltz, M. (2003). Form and Medium: A Mathematical Reconstruction. Image and Narrative, 6. 
Territorio como medium: Discusión sobre rendimientos analíticos para las observaciones de la $\mid 165$ complejidad socio-espacial

Schirmer, W. \& Hadamek, C. (2007). Steering as Paradox: The Ambiguous Role of the Political System in Modern Society. Cybernetics \& Human Knowing, 14(2-3), 133-150.

Sorens, J. (2011). Mineral Production, Territory, and Ethnic Rebellion: The Role of Rebel Constituencies. Journal of Peace Research, 48(5), 571-585.

Smith, A.D. (1983). Nationalism and Classical Social Theory. British Journal of Sociology, 34(1), 19-38.

Smith A. (1979). Investigación sobre la naturaleza y causas de la riqueza de las naciones. México DF: Fondo de Cultura Económica.

Suteneau, C. (2005). Complexity, Science and the Public: The Geography of a New Interpretation. Theory, Culture \& Society, 22(5), 113-140.

Tello, R. (2000). El espacio construido: los mecanismos de inclusión/exclusión. Planificación de la vivienda y determinaciones socio-culturales. In D. Provansal (Ed), Espacio y Territorio: Miradas antropológicas (pp. 13-22). Barcelona: Estudis d' Antropología social i cultural.

Ther, F. (2006). Complejidad territorial y sustentabilidad: Notas para una epistemología de los estudios territoriales. Horizontes Antropológicos, 12(25), 105-115.

Thrift N. (1999). The Place of Complexity Theory. Culture and Society, 16, 31- 69.

Torné, C. L. (2011). La valorización y dinamización de los paisajes para el desarrollo económicolocal. In M. Simancas \& A. Cortina (Eds), Retos y perspectivas de la gestión del paisaje de Canarias (pp. 412-435). Canarias: Observatorio del paisaje.

Tyulenev, S. (2012). Applying Lubmann to translation studies: Translation in society. UK: Routledge.

Uitermark J. \& Nicholls, W. (2015). Planning for Social Justice: Strategies, Dilemmas, Tradeoffs. Planning Theory, 16(1), 32-50.

Varela, E. (2015). Nuevos roles de los gobiernos locales en la implementación de políticas públicas. Gobernabilidad territorial y competitividad global. EURE, 41(123), 213-237.

Velazco, M. (2011). Confining Ethnic Territorial Autonomy in Colombia. The Journal of Environment \& Development, 20(4), 405 - 427.

Vera, P. (2017). Procesos de recualificación urbana e imaginarios de la innovación. El caso de Rosario, Argentina. EURE, 43(129), 209-234.

Vergara, N. (2009). Complejidad, espacio, tiempo e interpretación. Alpha, 28, 233-244.

Wacquant L. (2017). Bourdieu viene a la ciudad: Pertinencia, principios, aplicaciones. EURE, 43(129), 279-304.

Wacquant, L. (2015). Revisiting Territories of Relegation: Class, Ethnicity and State in the Making of Advanced Marginality. Urban Studies, 53(6), 1077-1088.

Wilkinson, C. (2011). Social-Ecological Resilience: Insights and Issues for Planning Theory. Planning Theory, 11(2), 148-169.

\section{SOBRE LOS AUTORES}

María Antonieta Urquieta. PhD en Trabajo Social, U Autónoma de Nuevo León, México. Académica, Jefa de carrera de Trabajo Social y Coordinadora del Núcleo Territorio y Diversidad del Departamento de Trabajo Social, Universidad de Chile.

César Mariñez. PhD en Filosofía mención Moral y Política, Universidad de Chile. Asistente de investigación e Investigador del Núcleo de Innovación y Políticas Públicas del Departamento de Trabajo Social, Universidad de Chile. 
166 | María Antonieta Urquieta, César Mariñez \& Catalina Jorquera

Catalina Jorquera. Magíster en Análisis Sistémico aplicado a la Sociedad, Universidad de Chile. Profesora de Estado en Historia, Geografía y Educación cívica, Universidad de la Frontera, Temuco.

\section{CONTACTO}

antonieta.urquieta@,uchile.cl

Recibido: mayo 2016

Aceptado: mayo 2017

REVISTA MAD | MAGÍSTER EN ANÁLISIS SISTÉMICO APLICADO A LA SOCIEDAD

ISSN 0718-0527

Departamento de Antropología

Facultad de Ciencias Sociales

Universidad de Chile

ఏ Avenida Capitán Ignacio Carrera Pinto 1045 Nuñoa 7800284 | Santiago | Chile

(c) +56229787760

(a) revistamad.uchile@,facso.cl

(\$) www.revistamad.uchile.cl

$\rightarrow \underline{\text { RevMadUChile Twitter | Facebook }}$ 